\title{
Analysis of hard coal quality for narrow size fraction under $20 \mathrm{~mm}$
}

\author{
Tomasz Niedoba ${ }^{1}$, and Paulina Pięta ${ }^{1, *}$ \\ ${ }^{1} \mathrm{AGH}$ - University of Science and Technology, Faculty of Mining and Geoengineering, Department \\ of Environmental Engineering and Mineral Processing, 30 A. Mickiewicz Av., 30-059 Kraków, \\ Poland
}

\begin{abstract}
The paper presents the results of an analysis of hard coal quality diversion in narrow size fraction by using taxonomic methods. Raw material samples were collected in selected mines of Upper Silesian Industrial Region and they were classified according to the Polish classification as types $31,34.2$ and 35 . Then, each size fraction was characterized in terms of the following properties: density, ash content, calorific content, volatile content, total sulfur content and analytical moisture. As a result of the analysis it can be stated that the best quality in the entire range of the tested size fractions was the 34.2 coking coal type. At the same time, in terms of price parameters, high quality of raw material characterised the following size fractions: $0-6.3 \mathrm{~mm}$ of 31 energetic coal type and $0-3.15 \mathrm{~mm}$ of 35 coking coal type. The methods of grouping (Ward's method) and agglomeration (k-means method) have shown that the size fraction below $10 \mathrm{~mm}$ was characterized by higher quality in all the analyzed hard coal types. However, the selected taxonomic methods do not make it possible to identify individual size fraction or hard coal types based on chosen parameters.
\end{abstract}

\section{The market of small and medium-sized hard coal products in Poland}

The IEC 2016 results indicate that fossil fuels remain dominant primary energy sources in the world as they will provide about $78 \%$ of total energy consumption in 2040. Globally, coal is still the second most frequently used energy source in the world, after oil and before natural gas, renewable energy, nuclear energy and lignite energy. Despite all trends, coal remains the main fuel in the power sector in Poland, both among small customers, as well as industrial plants.

In Polish hard coal processing plants, the enrichment of raw material in the full range of size is abandoned. One reason for this approach is prices of final products and market fluctuations. It is obvious that the use of higher quality parameter coal products have economic and environmental justification. Comparing unit prices of coal products for the same granulation and different calorific values, the higher cost of better quality assortments

\footnotetext{
*Corresponding author: ppieta@agh.edu.pl
} 
is only apparent. The real difference in gaining the same amount of energy from enriched coal and raw coal with the same granulation oscillates around $14 \%$ (in case of fine products). However, the additional costs are incurred during a purchase of lower quality coal, for example transport cost, which will constitute a disadvantage.

The pro-ecological actions of the government and the EU have resulted in a high demand for high-quality coal, called peas for commercial purposes, supplying retort boilers to private consumers, which has resulted in higher price and limited supply of the coal product since 2007. Facing this problem, the Institute of Chemical Processing of Coal has developed a technology that allows efficient burning of the fine coal in the retort boilers. The production of coal under $20 \mathrm{~mm}$ is maintained at a constant high level and the cost of fine is $10-15 \%$ lower than the peas [1-4]. However, the quality of coal types depends not only on maintaining the technological regime and a compliance with the developed control systems in coal processing plants, but it is largely determined by the natural characteristics of raw material, deciding on the possibilities of its using.

\section{Characteristic of raw materials}

The industrial suitability of fine-grained coal products for power and coking plants depends on many factors, but the most important ones are: calorific value, ash content or sulfur content. The basis for the rational use of coal in the combustion and coking process is knowledge of its qualitative characteristics and its correct assessment [1, 4].

Coal consists of combustible organic matter and ballast, which is a moisture and mineral substance. These are analytical components, the content of which is respectively within the following limits: $50-98 \%, 1-18 \%, 2-30 \%$. The organic and mineral substances come in many different chemical compounds and therefore comprehensive characterization can cover more than 40 individual determinations, which entail considerable financial effort and they are labor-intensive.

Heterogeneous coal construction is closely linked to the formation of the raw material. This includes such factors as: type of plant material, time, temperature, pressure, humidity and type of microorganisms. What serves as confirmation is the significant quality differentiation of hard coal in Polish coal basins, mines or even stratum exploited in a single mining plant $[2,5]$.

The commercial and industrial assessment of hard coal requires the determination of certain analytical parameters characterizing the energy source in terms of its thermal resistance, ballast quantity and calorific value. In order to examine these characteristics a technical analysis is carried out under which the moisture content, ash and volatiles, as well as the heat of combustion and calorific value are determined. These properties constitute an important element in settlements between mining plants and consumers [5, 6].

Quantitative and qualitative characteristics of the basic components of coal and its physicochemical properties are an important element for selecting an optimal processing and use method. As the range of end users is wide and the properties of the raw material are different, there exists i.a. the Polish classification of hard coal which systematizes particular information (PN-ISO 11760: 2007P). However, in the era of the development of modern and highly efficient combustion technology of the discussed solid fuel and the deterioration of the quality of deposits, it is necessary to analyze thoroughly the properties of fine coal fractions, whose market share is predominant. 


\section{Materials and methods}

The paper presents the results of analyzes of differentiation of hard coal properties in narrow size fraction. Raw material samples were collected in selected mines of Upper Silesian Industrial Region and they were classified according to Polish classification as types: $31,34.2$ and 35 . As a result of the sieve analysis, 9 size fraction were obtained: $0-1$, $1-3.15,3.15-6.3,6.3-8,8 .-10,10-12.5,12.5-14,14-16,16-20[\mathrm{~mm}]$ for each sample. They were further characterized by the following characteristics: density $(\rho)$, ash content (A), calorific value $(\mathrm{Q})$, volatile content $(\mathrm{V})$, total sulfur content $(\mathrm{S})$ and analytical moisture (W).

The complex nature of hard coal is described by the 7-dimensional vector of properties of the grained material $\bar{W}(1)$, in which measurable and non-measurable variables are included [7-10]:

$$
\bar{W}=[\text { coal type }, d, \rho, A, Q, V, S, W]
$$

The application of multidimensional characterization of the raw material allows numerous relationships and a more detailed description of the properties to reach better understanding of the topic. Problems of mineral processing were considered according to the multidimensional description in the following work [7, 11-16].

The taxonomic methods were used to order and classify the experimental data concerning size fractions of various types of hard coal. It is not a very common way of consideration the nature of the mineral processing issues, but cluster analysis has been used in following work successfully [17-24].

The application of multidimensional comparative analysis requires the formation of a $\mathrm{Z}$ (2) unitarized data matrix. The process of unitarization is an extremely important element from the point of view of elimination of the influence of scale on the results of grouping and agglomeration. Based on these values, the taxonomic distance matrix D (square matrix of $n \times n$ ) is defined (4). There is a large number of metrics that use a different approach to transform the description of phenomena from n-dimensional space into a straight line. The Euclidean distance $\mathrm{d}_{\mathrm{ij}}(3)$ was used in the paper as a measure of the variability of the hard coal pairs studied. Another element of cluster analysis is the selection of the appropriate hierarchical method, which is the grouping algorithm of the analyzed cases. For the purpose of the analysis of hard coal quality and the creation of a dendrogram, the Ward method (5) was used, where the sum of squared deviations within the assumed groups is minimized. A detailed description of the steps involved in the implementation of different taxonomic methods can be found in the following work [11, 18, 25].

$$
\begin{gathered}
Z=\left[\begin{array}{cccc}
z_{11} & z_{12} & \cdots & z_{1 l} \\
z_{21} & z_{21} & \cdots & z_{2 l} \\
\cdots & \cdots & \cdots & \cdots \\
\cdots & \cdots & \cdots & \cdots \\
z_{n 1} & z_{n 2} & \cdots & z_{n l}
\end{array}\right] \\
d_{i j}=\sqrt{\sum_{p=1}^{n}\left(z_{p i}-z_{p j}\right)^{2}}
\end{gathered}
$$




$$
\begin{gathered}
D=\left[\begin{array}{cccc}
0 & d_{12} & \cdots & d_{1 l} \\
d_{21} & 0 & \cdots & d_{2 l} \\
\cdots & \cdots & \ddots & \cdots \\
d_{l 1} & d_{l 2} & \cdots & 0
\end{array}\right]_{[n \times n]} \\
E S S=\sum_{i=1}^{k}\left(x_{i j}-\bar{x}_{J}\right)^{2}
\end{gathered}
$$

where: $\quad n$-number of examined cases, i.e. coal types and size fractions,

$l$ - number of random variable, i.e. number of parameters,

$z_{i j}$ - unitarized value of $\mathrm{x}_{\mathrm{j}}$ property, which was calculated according to formula:

$z_{i}=\frac{x_{i}}{x_{\max }-x_{\min }}$

$x_{i}$ - the value of a single property measurement,

$x_{\max }, x_{\min }$ - the maximum and minimum value of the property,

$x_{i k}$ - the value of the property for the each cluster at the mean value of the characteristic $\bar{x}$,

$k$ - the number of elements in a cluster.

\section{Results and discussion}

In order to present the chosen question a qualitative analysis of selected coal types in a narrow range of particle size less than $20 \mathrm{~mm}$ was performed. A cluster analysis was used to investigate the structure of hard coal quality parameters. Tab. 1 summarizes data as a starting point for further assessing the variability of size fraction properties.

Table 1. The matrix of unitarized value of qualitative coal parameters.

\begin{tabular}{|l|c|c|c|c|c|c|}
\hline Coal type (d) & $\mathbf{\rho}$ & $\mathbf{Q}$ & $\mathbf{A}$ & $\mathbf{S}$ & $\mathbf{V}$ & $\mathbf{W}$ \\
\hline $\mathbf{3 1}(\mathbf{1})$ & 3.037974 & 1.232133 & 0.444946 & 0.250241 & 1.750197 & 1.191265 \\
\hline $\mathbf{3 1} \mathbf{( 3 . 1 5 )}$ & 2.849456 & 1.353137 & 0.297351 & 0.208513 & 1.856297 & 1.121108 \\
\hline $\mathbf{3 1}(\mathbf{6 . 3})$ & 3.145346 & 1.308598 & 0.330727 & 0.263389 & 1.878694 & 0.930461 \\
\hline $\mathbf{3 1}(\mathbf{8})$ & 3.244557 & 1.077405 & 0.695272 & 0.179093 & 1.431426 & 0.788933 \\
\hline $\mathbf{3 1}(\mathbf{1 0 )}$ & 3.552371 & 0.838955 & 0.95161 & 0.187945 & 1.284642 & 0.74155 \\
\hline $\mathbf{3 1}(\mathbf{1 2 . 5 )}$ & 3.486440 & 0.861240 & 0.938284 & 0.217675 & 1.301985 & 0.731613 \\
\hline $\mathbf{3 1} \mathbf{( 1 4 )}$ & 3.542248 & 0.757164 & 1.025184 & 0.164913 & 1.297361 & 0.65390 \\
\hline $\mathbf{3 1}(\mathbf{1 6 )}$ & 3.607795 & 0.773379 & 1.031595 & 0.302379 & 1.257185 & 0.67845 \\
\hline $\mathbf{3 1}(\mathbf{2 0})$ & 3.736203 & 0.664083 & 1.154617 & 0.168892 & 1.179073 & 0.680875 \\
\hline $\mathbf{3 4 . 2 ( 1 )}$ & 2.736203 & 1.664083 & 0.154617 & 0.107378 & 1.796995 & 0.191265 \\
\hline $\mathbf{3 4 . 2}(\mathbf{3 . 1 5})$ & 3.070923 & 1.393565 & 0.432640 & 0.126284 & 1.430637 & 0.236474 \\
\hline
\end{tabular}




\begin{tabular}{|c|c|c|c|c|c|c|}
\hline $34.2(6.3)$ & 2.748028 & 1.599577 & 0.223936 & 0.090345 & 1.670455 & 0.311218 \\
\hline $34.2(8)$ & 2.808994 & 1.540958 & 0.280232 & 0.087022 & 1.612480 & 0.329088 \\
\hline $34.2(10)$ & 2.841770 & 1.521321 & 0.324632 & 0.088438 & 1.576281 & 0.400133 \\
\hline $34.2(12.5)$ & 2.849267 & 1.514370 & 0.320033 & 0.07742 & 1.57281 & 0.298834 \\
\hline 34.2 (14) & 3.368400 & 1.055552 & 0.727415 & 0.115825 & 1.277294 & 0.251008 \\
\hline $34.2(16)$ & 2.955492 & 1.644815 & 0.330215 & 0.089411 & 1.466929 & 0.290437 \\
\hline $34.2(20)$ & 2.764356 & 1.426877 & 0.41377 & 0.091261 & 1.466126 & 0.355175 \\
\hline $35(1)$ & 2.884867 & 1.498100 & 0.352919 & 0.100936 & 1.192387 & 0.312277 \\
\hline $35(3.15)$ & 3.047743 & 1.340802 & 0.510616 & 0.100471 & 1.121604 & 0.310905 \\
\hline $35(6.3)$ & 3.329298 & 1.141705 & 0.714939 & 0.109130 & 1.002651 & 0.404173 \\
\hline $35(8)$ & 3.502603 & 0.986963 & 0.879483 & 0.103406 & 0.939860 & 0.388168 \\
\hline $35(10)$ & 3.407665 & 1.058374 & 0.805628 & 0.095228 & 1.022796 & 0.416712 \\
\hline $35(12.5)$ & 3.515951 & 0.973397 & 0.897462 & 0.092415 & 0.93192 & 0.389232 \\
\hline $35(14)$ & 3.734799 & 0.798653 & 1.074937 & 0.074777 & 0.885933 & 0.417079 \\
\hline $35(16)$ & 3.711644 & 0.799705 & 1.079979 & 0.077208 & 0.881488 & 0.386538 \\
\hline $35(20)$ & 3.735637 & 0.787784 & 1.104560 & 0.074470 & 0.878694 & 0.392187 \\
\hline
\end{tabular}

The most direct method of calculating the distance between the coal pairs in a multidimensional space is a determination of Euclidean distance (3). On the basis of this method, agglomeration of Ward method was conducted (5). The algorithm allowed to find coal types that were the closest in terms of size fractions quality. A graphical interpretation of this method is the dendrogram (Fig. 1). On the other hand, the stages of drawing up the agglomeration graph are shown in Fig. 2.

The ratio for determining the quality of the each coal type is the taxonomic distance (6):

$$
D E=d_{j}=\sqrt{\sum_{i=1}^{n}\left(1-s_{j i}\right)^{2}}
$$

where: $s_{j i}=\frac{z_{j i}}{z_{j \max }}, i=1, \ldots, l ; j=1, \ldots, n$. 


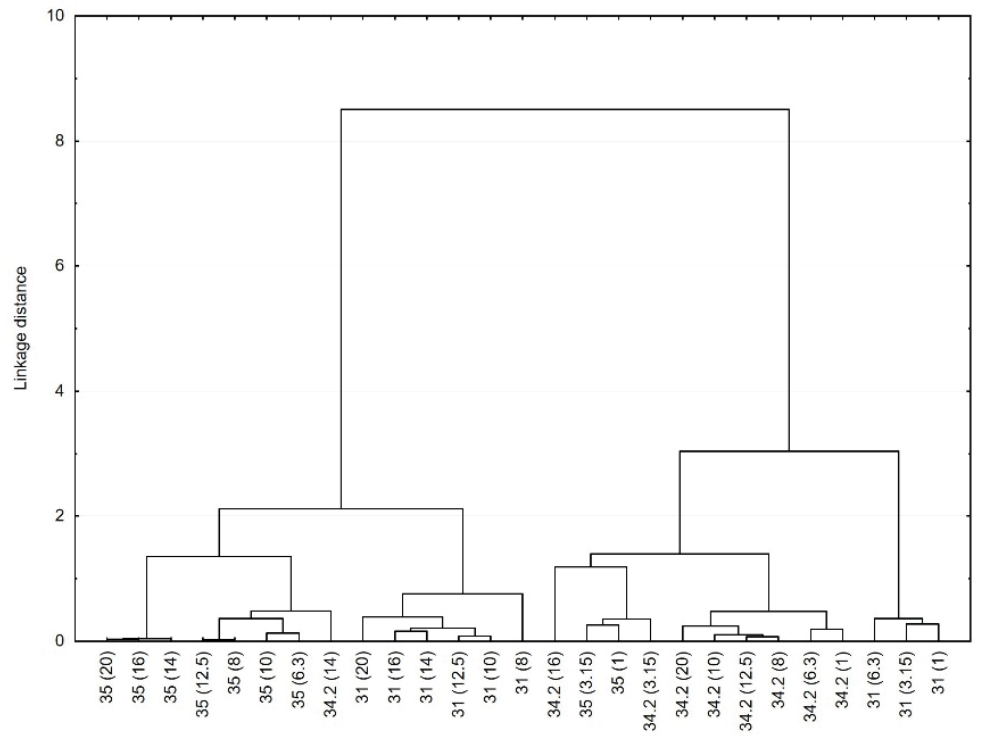

Fig. 1. Dendrogram of examined size fractions and coal types (Ward method).

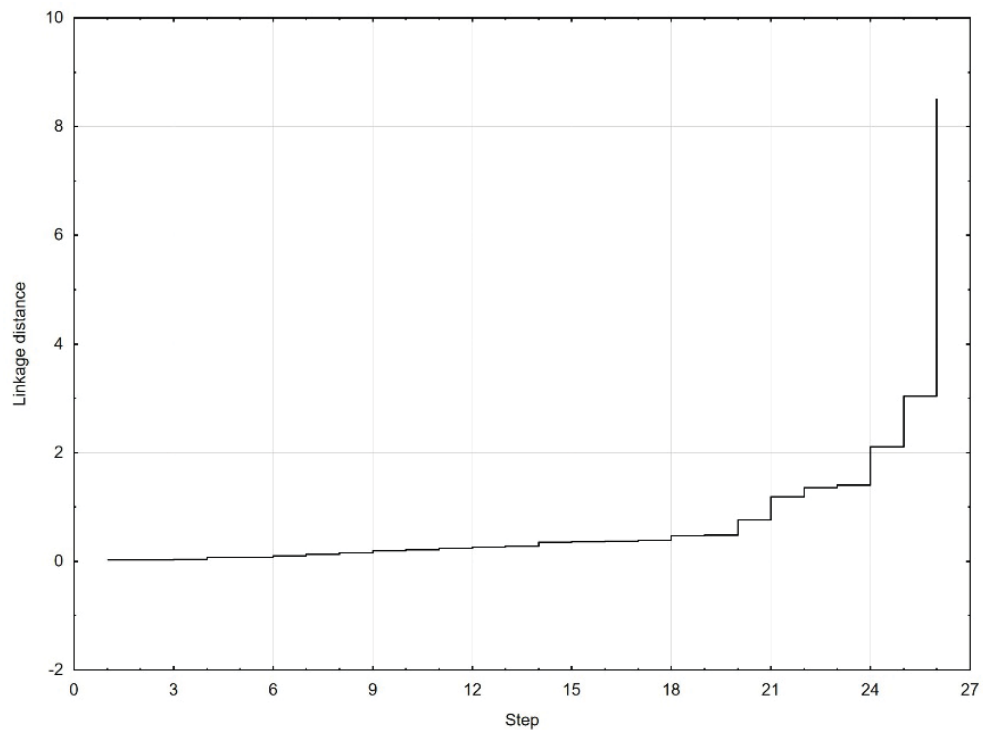

Fig. 2. Steps of dendrogram creation.

Table 2. Summary data to assess the quality of the size fraction and coal types.

\begin{tabular}{|l|c|c|c|c|c|c|}
\hline Coal type (d) & $\mathbf{1} / \mathbf{\rho}$ & $\mathbf{Q}$ & $\mathbf{1 / A}$ & $\mathbf{1 / S}$ & $\mathbf{V}$ & $\mathbf{1} / \mathbf{W}$ \\
\hline $\mathbf{3 1} \mathbf{( 1 )}$ & 0.329167 & 1.232133 & 2.247464 & 3.996154 & 1.750197 & 0.839444 \\
\hline $\mathbf{3 1} \mathbf{( 3 . 1 5 )}$ & 0.350944 & 1.353138 & 3.363025 & 4.795864 & 1.856297 & 0.891975 \\
\hline $\mathbf{3 1} \mathbf{( 6 . 3 )}$ & 0.31793 & 1.308599 & 3.02364 & 3.796666 & 1.878694 & 1.074736 \\
\hline
\end{tabular}




\begin{tabular}{|c|c|c|c|c|c|c|}
\hline $31(8)$ & 0.308208 & 1.077405 & 1.438286 & 5.583685 & 1.431426 & 1.267535 \\
\hline $31(10)$ & 0.281502 & 0.838955 & 1.050841 & 5.320704 & 1.284642 & 1.348511 \\
\hline $31(12.5)$ & 0.286826 & 0.86124 & 1.065776 & 4.594012 & 1.301985 & 1.366843 \\
\hline $31(14)$ & 0.282307 & 0.757164 & 0.975434 & 6.063814 & 1.297361 & 1.529076 \\
\hline $31(16)$ & 0.277178 & 0.773379 & 0.969373 & 3.307105 & 1.257185 & 1.473929 \\
\hline $31(20)$ & 0.267651 & 0.664083 & 0.866088 & 5.920932 & 1.179073 & 1.468699 \\
\hline 34.2 (1) & 0.36547 & 1.664083 & 6.467604 & 9.312868 & 1.796995 & 5.228359 \\
\hline $34.2(3.15)$ & 0.325691 & 1.393565 & 2.31139 & 7.918671 & 1.430637 & 4.228801 \\
\hline $34.2(6.3)$ & 0.363897 & 1.599578 & 4.465554 & 11.06864 & 1.670455 & 3.21318 \\
\hline $34.2(8)$ & 0.355999 & 1.540958 & 3.568476 & 11.49137 & 1.61248 & 3.038702 \\
\hline $34.2(10)$ & 0.351893 & 1.521322 & 3.080409 & 11.30732 & 1.576281 & 2.49917 \\
\hline $34.2(12.5)$ & 0.350967 & 1.51437 & 3.124675 & 12.91507 & 1.57281 & 3.346343 \\
\hline $34.2(14)$ & 0.296877 & 1.055552 & 1.374731 & 8.633729 & 1.277295 & 3.983941 \\
\hline $34.2(16)$ & 0.338353 & 1.644815 & 3.028325 & 11.18425 & 1.466929 & 3.443088 \\
\hline $34.2(20)$ & 0.361748 & 1.426877 & 2.416802 & 10.95753 & 1.466126 & 2.815512 \\
\hline $35(1)$ & 0.346636 & 1.4981 & 2.833512 & 9.907242 & 1.192387 & 3.202282 \\
\hline $35(3.15)$ & 0.328112 & 1.340802 & 1.958421 & 9.953124 & 1.121604 & 3.21642 \\
\hline $35(6.3)$ & 0.300364 & 1.141705 & 1.39872 & 9.163358 & 1.002651 & 2.474187 \\
\hline $35(8)$ & 0.285502 & 0.986964 & 1.137032 & 9.670653 & 0.93986 & 2.576205 \\
\hline $35(10)$ & 0.293456 & 1.058374 & 1.241267 & 10.50112 & 1.022796 & 2.399739 \\
\hline $35(12.5)$ & 0.284418 & 0.973397 & 1.114253 & 10.8207 & 0.931929 & 2.569164 \\
\hline $35(14)$ & 0.267752 & 0.798653 & 0.930287 & 13.37308 & 0.885934 & 2.397627 \\
\hline $35(16)$ & 0.269422 & 0.799705 & 0.925944 & 12.95202 & 0.881488 & 2.587067 \\
\hline $35(20)$ & 0.267692 & 0.787784 & 0.905338 & 13.42814 & 0.878694 & 2.549803 \\
\hline
\end{tabular}

The results of the analysis of the price parameters of the raw materials are presented in Table 3 . 
Table 3. Evaluation of hard coal quality based on Euclidean distance.

\begin{tabular}{|c|c|c|c|c|c|}
\hline Coal type (d) & DE & Coal type (d) & DE & Coal type (d) & DE \\
\hline $31(1)$ & 1.306034 & $34.2(1)$ & 0.309537 & 35 (1) & 0.825045 \\
\hline $31(3.15)$ & 1.169706 & $34.2(3.15)$ & 0.844396 & $35(3.15)$ & 0.954841 \\
\hline $31(6.3)$ & 1.221354 & $34.2(6.3)$ & 0.537645 & $35(6.3)$ & 1.157722 \\
\hline $31(8)$ & 1.313538 & $34.2(8)$ & 0.650659 & $35(8)$ & 1.215767 \\
\hline $31(10)$ & 1.419609 & $34.2(10)$ & 0.778689 & $35(10)$ & 1.171355 \\
\hline 31 (12.5) & 1.431495 & $34.2(12.5)$ & 0.659067 & 35 (12.5) & 1.207031 \\
\hline $31(14)$ & 1.402514 & $34.2(14)$ & 1.037122 & $35(14)$ & 1.283496 \\
\hline $31(16)$ & 1.503578 & $34.2(16)$ & 0.693524 & $35(16)$ & 1.269353 \\
\hline $31(20)$ & 1.466693 & $34.2(20)$ & 0.841281 & $35(20)$ & 1.2784 \\
\hline
\end{tabular}

* shaded fields mean coals with the best costogenic parameters

The best quality characterizes the coking coal (34.2) with particle size of 0-12.5 mm and $14-20 \mathrm{~mm}$, and the second coking coal (35) in narrower granulation $(0-3.15 \mathrm{~mm})$. For these cases the index values are the lowest.

Subsequently, the k-means grouping was performed, in which the algorithm assigned the cases as described in Tab. 4. Fig. 3 shows the distribution of mean values in both groups.

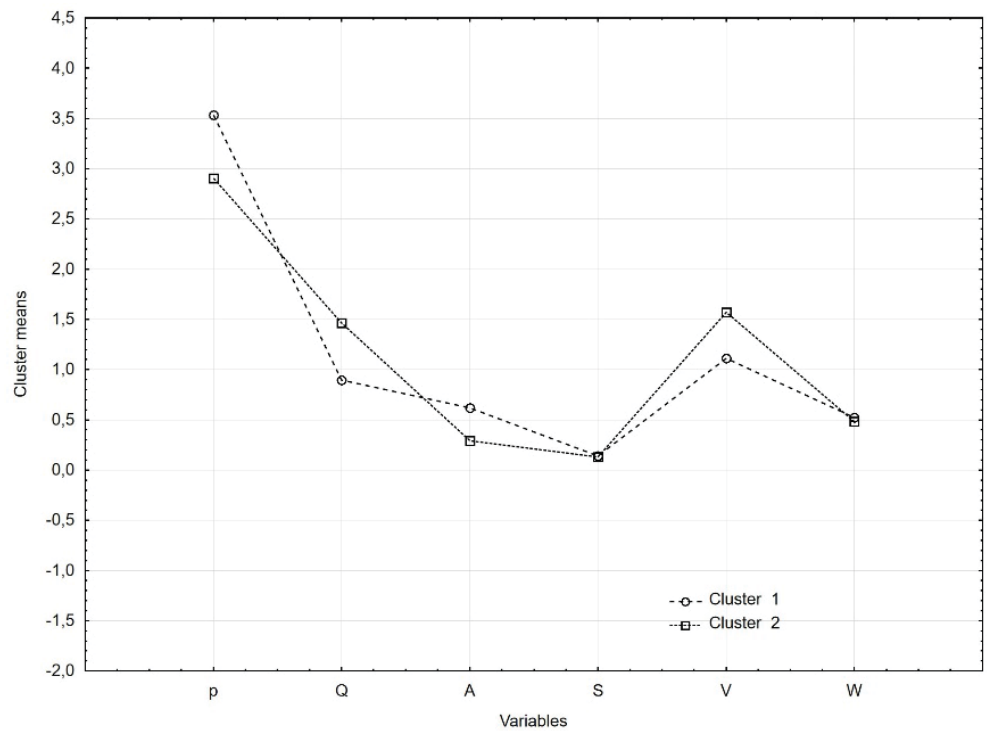

Fig. 3. Distribution of mean values of parameters in cluster assigned k-means method.

Table 4. Summary cases grouped in two clusters by k-means method. 


\begin{tabular}{|c|c|}
\hline Cluster $\mathbf{1}$ & Claster 2 \\
\hline $31(8)$ & $31(1)$ \\
$31(10)$ & $31(3.15)$ \\
$31(12.5)$ & $31(6.3)$ \\
$31(14)$ & $34.2(1)$ \\
$31(16)$ & $34.2(3.15)$ \\
$31(20)$ & $34.2(6.3)$ \\
$34.2(14)$ & $34.2(8)$ \\
$35(6.3)$ & $34.2(10)$ \\
$35(8)$ & $34.2(12.5)$ \\
$35(10)$ & $34.2(16)$ \\
$35(12.5)$ & $34.2(20)$ \\
$35(14)$ & $35(1)$ \\
$35(16)$ & $35(3.15)$ \\
$35(20)$ & \\
\hline
\end{tabular}

Cluster no. 1 includes the following size fractions: 8-20 mm (31 coal type), 12.5-14 mm (34.2 coal type), $6.3-20 \mathrm{~mm}$ (35 coal type), which exhibit poorer quality as compared to the other cases. In cluster area no. 2 there are: energetic coal 31 type with granulation 0-6.3 $\mathrm{mm}$, a coking coal 34.2 type with granulation $0-12.5 \mathrm{~mm}$ and $14-20 \mathrm{~mm}$, and a coking coal 35 type with particle size $0-3.15 \mathrm{~mm}$. Based on Fig. 3, it was found that group no. 1 had higher mean density values and ash content, while group no. 2 was characterized by higher calorific content and volatile content. Parameters such as moisture and sulfur content did not significantly affect the differentiation between the coals. The following parameters were most important in grouping the chosen method: density, calorific value, ash content and volatiles. These conclusions were obtained through an analysis of variance (Tab. 5), which is an extremely useful tool for investigating the impact of certain factors of the phenomenon under consideration.

Table 5. Analysis of variance.

\begin{tabular}{|c|c|c|c|}
\hline Variables & Test $\mathbf{F}$ & Probability level p & \multirow{7}{*}{$\begin{array}{l}\text { The verification } \\
\text { of assumptions: } \\
\qquad \mathrm{p}<0.05\end{array}$} \\
\hline $\mathrm{p}$ & 121,8886 & 0,000000 & \\
\hline Q & 108,5164 & 0,000000 & \\
\hline A & 20,1889 & 0,000139 & \\
\hline $\mathrm{S}$ & 0,1844 & 0,671288 & \\
\hline V & 30,4180 & 0,000010 & \\
\hline W & 0,1435 & 0,708032 & \\
\hline
\end{tabular}

Conducting further qualitative analysis of the distinguished clusters of coals and size fractions a more precise segregation of the raw material was possible. In cluster no. 1 with poorer quality parameters, 3 subgroups were diversified, mainly in terms of ash content, caloric content and volatiles content. Among them the best quality was in the size fractions 6.3-8 $\mathrm{mm}(31), 12-14 \mathrm{~mm} \mathrm{(34.2)} \mathrm{and} \mathrm{3.15-10} \mathrm{mm}$ (35), slightly worse parameters were recorded in 35 coking coal with granulation $6.3-20 \mathrm{~mm}$, whereas energetic coal with 
granulation $8-20 \mathrm{~mm}$ was characterized by the weakest quality. In cluster no. 2 also an internal division of cases into 3 subgroups was possible. According to the results of assessment based on Euclidean distance, the first and the highest quality subgroup consisted of 34.2 coking coal practically throughout the whole grain size range, excluding one size fraction (12-14 mm), and 35 coking coal (1-3.15 mm). Other types of coal were segregated into two separate internal clusters. The weakest quality was energetic coal with a granulation 0-3.15 $\mathrm{mm}$, while the size fraction $3.15-6.3 \mathrm{~mm}$ of the same raw material was characterized by a slightly higher quality. Three parameters proved to have the greatest influence on the division within the cluster no. 2: moisture content, sulfur content, calorific value.

\section{Conclusions}

The applied methods of cluster analysis enabled detailed examination of hard coal quality in narrow size fractions, as well as their classification. However, the selected taxonomic methods do not make it possible to identify individual size fractions or types of hard coal based on chosen parameters. As a result of the analysis it can be stated that the 34.2 coking coal in the whole range of grain can be characterized by the best quality, at the same time in terms of price parameters the size fractions $0-3.15 \mathrm{~mm}$ of 35 coking coal type and $0-6.3$ $\mathrm{mm}$ of 31 energetic coal matched. The methods of grouping and agglomeration have shown that in all the analyzed hard coal types the size fractions below $10 \mathrm{~mm}$ were distinguished by higher quality.

The good quality of fine coal is one of the reasons why enrichment operations in the full range of grain size have not been introduced in some Polish hard coal preparation plants. However, more and more price parameters of hard coal are deteriorating, and the expanding operation includes coking coal decks, to which the technological systems of processing plants are not adapted largely. In contrast, in the structure of production of commercial sorts, a fine coal accounted for a significant part, about $80-90 \%$. An accurate technical analysis of hard coal with a granulation $0-20 \mathrm{~mm}$ is an important element due to the continuing structure of coal production and the need to adapt domestic furnaces and boilers for solid fuels produced.

\section{References}

1. W. Wawrzynkiewicz, Journal of the Polish Mineral Engineering Society, 4(1), 27-37 (2003)

2. T. Olejnik, A. Surowiak, T. Gawenda, T. Niedoba, T. Tumidajski, AGH Journal of Mining and Geoengineering, 4(1), 207-216 (2010)

3. J. Zawistowski, S. Janiszewski, Rynek Instalacji, 7(8), 52-56 (2010)

4. J. Grabowska, Logistyka, 2, 579-588 (2012)

5. A. Karcz, Coke engineering Vol. I, (AGH, Cracow, 1991)

6. A. Surowiak, Journal of the Polish Mineral Engineering Society, 32, 153-158 (2013)

7. T. Tumidajski, MRM, 23(6), 111-123 (2010)

8. T. Niedoba, A. Surowiak, Proceedings of the XXVI International Mineral Processing Congress, Vol. 1, 3844-3854 (2012)

9. T. Niedoba, Bulletin of the Mineral and Energy Economy Research Institute of the Polish Academy of Sciences, Cracow (2013)

10. T. Niedoba, Physicochem Probl Mi, 49(1), 175-188 (2013) 
11. C. Aldrich, Exploratory Analysis of Metallurgical Process Data with Neural Networks and Related Methods. Process Metallurgy 12 (Elsevier Science B.V., Netherlands, 2002)

12. T. Niedoba, Wielowymiarowe charakterystyki zmiennych losowych $w$ opisie materiatów uziarnionych $i$ procesów ich rozdziału (Wydawnictwo Instytutu Gospodarki Surowcami Mineralnymi i Energią PAN, Kraków, 2013)

13. T. Niedoba, D. Jamróz, Arch. Min. Sci., 58(4), 1317-1331 (2013)

14. F. Nakhaei, M. Irannajad, A. Sam, A. Jamalzadeh, Physicochem. Probl. Mi., 52 (1), 252-267 (2015)

15. T. Niedoba, A. Surowiak, P. Pięta, J. Pol. Miner. Eng. Soc., 17(1), 15-22 (2016)

16. T. Niedoba, P. Pięta, A. Surowiak, D. Jamróz, MEC2016, E3S Web of Conferences, 8, 01036 (2016)

17. K. Pulkkinen, R. Ylinen, S.-L. ämsä-Jounela, M. Järvensivu, XVIII International Mineral Processing Congress, Sydney, Parkville, Australia, 325-334 (1993)

18. D.W. Ginsberg, W.J. Whiten, Trans. Instn. Min. Metall., 100, 139-146 (1991)

19. D.W. Ginsberg, W.J. Whiten, Int. J. Miner. Process., 36, 63-79 (1992)

20. D.W. Ginsberg, W.J. Whiten, Miner. Eng., 6(1), 31-40 (1993)

21. S. Laine, H. Lappalainen, S.-L. Jämsä-Jounela, Miner. Eng., 8(6), 637-648 (1995)

22. J.R. Whiteley, J.F. Davis, Comput. Chem. Eng., 16(4), 329-346 (1992)

23. J.R. Whiteley, J.F. Davis, Comput. Chem. Eng., 18(7), 637-661 (1994)

24. C. Aldrich,.CEC, 177(1), 121-137 (2000)

25. A. Stanisz, The accessible statistics course using STATISTICA PL on examples from medicine. Multidimensional analysis (StatSoft, Cracow, 2007) 